\title{
Preliminary study: Predictors for success in an important premedical subject at a South African medical school
}

\author{
N J Allers, MSc, PhD, BEd; L Hay, MSc, PhD; R C Janse van Rensburg, BSc, BA Hons
}

Department of Human Physiology, Sefako Makgatho Health Sciences University, Pretoria, South Africa

Corresponding author: N J Allers (nico.allers14@gmail.com)

\begin{abstract}
Background. Admission to Sefako Makgatho Health Sciences University, Pretoria, South Africa is determined by the student's Matriculation (Matric) results, while the writing of the National Benchmark Test (NBT) is not compulsory. An average student pass rate of $80.1 \%$ in physiology (MB ChB II) in the past 13 years compelled this institution to investigate which criteria in the selection process could be predictors for success in physiology, a fundamental discipline for medical studies.

Objectives. To compile a profile of very successful physiology students and those who failed the subject, and to identify predictors for success in physiology. Methods. A quantitative study, using Matric and available NBT results, was conducted among the MB ChB II group (N=228) of 2011. Two target groups were identified: highly successful students in physiology $(n=37)$ and those who failed $(n=46)$. Statistical analysis of the results was performed on SAS 9.2, Microsoft Windows (SAS Institute Inc., USA) ( $p$-values $\leq 0.05$ are significant) using the $t$-test, Fisher's exact test and the simple linear regression test.

Results. These indicated that a good Matric symbol $(\geq 5)$ in English and life science and a good performance in the quantitative literacy domain of the NBT were statistically significant predictors for success in physiology.

Conclusion. This preliminary study indicates the need for our institution to rethink the effectiveness of the selection criteria, redesign the selection process of students for the $\mathrm{MB} \mathrm{ChB}$ course, and consider making use of the NBT.
\end{abstract}

Afr J Health Professions Educ 2016;8(1):81-83. DOI:10.7196/AJHPE.2016.v8i1.647

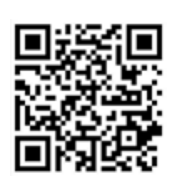

\section{Background}

The criteria and processes to select students for the $\mathrm{MB} \mathrm{ChB}$ course have been the subject of much controversy and debate over the past 20 years, as these represent the main mechanisms by which racial and gender imbalances in student profiles can be rectified. ${ }^{[1-4]}$ Consequently, all medical schools have in recent years evaluated and adapted their selection criteria and processes. ${ }^{[5,6]}$ Most South African (SA) medical schools use academic and non-academic criteria to select students, the former accounting for $70-80 \%$ of admission requirements. ${ }^{[5]}$ Some authors suggest that previous academic performances alone are not a fair reflection of some other very important characteristics required to be successful at medical school..$^{[5]}$ Academic criteria emphasise an overall Matriculation (Matric) pass rate (the $\mathrm{M}$-score) and subject choices; recently, the National Benchmark Test (NBT) was also introduced. ${ }^{[5,7,8]}$

The National Senior Certificate (NSC) is the school-leaving certificate in SA and replaced the Senior Certificate in 2008. Pupils study at least six subjects from six different groups, including two compulsory official SA languages - a first and second language - and four selected subjects. Requirements for Matric pass rates vary, as do those for subject choices. Most medical schools require Matric physical science and mathematics, and in some cases life science, while some also have language requirements. ${ }^{[5]}$

The NBT was a 3-year project commissioned by Higher Education SA, designed as an instrument to assess the NSC system, and calibrated against the previous Matric system. A second and equally important goal of the NBT was to help to assess the validity of the NCS results as a predictor of success in university studies. The NBT provides information about the competence of students with regard to three core domains of knowledge and skills, i.e. academic literacy (AL), quantitative literacy (QL) and mathematics (MA). The tests are written during the year before university entry or at the beginning of the year of entry. Research indicated that many students lack quantitative concepts and techniques that medical courses appear to assume students have. ${ }^{[6]}$ Although all medical students have studied MA at school, it does not necessarily mean that they are prepared for the QL demands of the curriculum. School MA does not include applying the mathematical techniques in real contexts and the statistical content of the school MA curriculum is very limited. ${ }^{[7]}$

\section{Problem setting}

During recent years, more applicants at Sefako Makgatho Health Sciences University, Pretoria, SA have come from diverse educational, linguistic, cultural and socioeconomic backgrounds. At this university, admission to medical studies is primarily based on the academic abilities of the student and determined by the student's Matric results. Lately, the students have also written the NBT, but it is not currently used in the selection process. An average student pass rate of $80.1 \%$ in physiology (MB ChB II) in the past 13 years compelled the institution to investigate which factors are predictors of success or failure in this subject. Failure to pass physiology often prevents students from continuing their medical studies. The information obtained by means of this study can be used to identify factors that place students at risk of failure.

\section{Objectives}

The objectives of the study were to analyse existing data (Matric and NBT results) of the $2011 \mathrm{MB}$ ChB II group; to compile profiles of successful students and those who failed physiology; and to identify predictors for success in physiology.

\section{Methods Sampling of specific target groups}

Although the study included data from all 2011 2nd-year medical students $(N=228)$, two specific target groups were identified for comparison, i.e. 
highly successful students in physiology, with a final mark of $\geq 65 \%$ ( $n=36$; group 1 ), and those who failed physiology, with a final mark of $<50 \%$ ( $n=45$; group 2). The performance of these two groups was compared with regard to the four Matric subjects that were used for their selection, i.e. MA, English, life science and physical science, and also for the NBT results.

\section{Time schedule}

Data were analysed after the final physiology results became available.

\section{Data analysis}

Statistical analysis of the quantitative results was done by the Statistical Consultation Service of the University of Limpopo, Medunsa Campus. All statistical procedures were performed on SAS 9.2, Microsoft Windows (SAS Institute Inc., USA) ( $p$-values $\leq 0.05$ are significant) using the $t$-test, Fisher's exact test and the linear regression test. The last test was used to determine the extent to which there is a linear relationship between the dependent variable (final mark in physiology) and $\geq 1$ independent variables.

\section{Results}

Scores for the subjects that were used in the selection process (MA, physical science, life science and English) were taken in consideration. The grading systems for the subjects were between level 5 and 7 - level 5 was the cut-off point. For level 5 a student has to obtain $60-69 \%$ in a subject, which was regarded as an aboveaverage achievement.

The Matric and NBT results for the two groups are presented in Table 1.

\section{Discussion \\ Matric results}

As students were selected on the basis of their performance in only four of their Matric subjects, one has to assume that they performed relatively well in these subjects. The overall combined mark also plays a role in the selection; therefore, it does not necessarily mean that they achieved high marks in all four of the subjects. Our study objective was to establish whether performing better in one or more of these subjects could be to the student's advantage while studying physiology.

Higher education institutions in SA mainly use English as the language of preference. At our institution, English is not the mother tongue of the majority of students. The language issue might be more unique to $\mathrm{SA}$, as minority groups from disadvantaged backgrounds in countries such as the USA and UK are more likely to have been exposed to the language of tuition. At our institution the majority of students come from disadvantaged backgrounds, with little exposure to English. The significance of language is highlighted by the results, which indicated that the successful group had significantly higher marks for English in Matric than their counterparts who failed physiology. A similar tendency was seen for students with English as a home language, but it was not statistically significant, probably due to the low number of students in this category.

The other subject in which the successful group showed significantly better results, was life science. The results were supported by the linear regression test. Linear regression analysis for the entire group of students $(N=228)$ showed that of the four Matric subjects, life science was the only statistically significant predictor of the final mark in physiology $(p=0.0006)$.

This result was not completely unexpected, as the school syllabus for life science provides a good foundation for physiology. Similar observations were made in both the USA and UK. ${ }^{[9,10]}$ In these countries, chemistry also correlated well with a good performance in medical studies. In SA, however, chemistry is part of physical science,

Table 1. Matric and NBT results

\begin{tabular}{|c|c|c|c|}
\hline \multicolumn{4}{|l|}{ Table 1. Matric and NBT results } \\
\hline \multicolumn{4}{|c|}{ Matric: students with a $\geq$ level 5 gradation ${ }^{*}$ in the four essential Matric subjects (Fisher's exact test) } \\
\hline \multirow[b]{2}{*}{ Matric subject } & $\begin{array}{l}\text { Group 1: students } \\
\text { highly successful in } \\
\text { physiology }(n=36)\end{array}$ & $\begin{array}{l}\text { Group 2: students } \\
\text { who failed physiology } \\
(n=45)\end{array}$ & \multirow{2}{*}{$p$-value } \\
\hline & $n(\%)$ & $n(\%)$ & \\
\hline English (home language) & $10(80.0)$ & $6(66.7)$ & 0.60 \\
\hline English (first additional language) & $26(84.6)$ & $39(61.5)$ & $0.05^{*}$ \\
\hline Life science & $36(91.7)$ & $45(62.2)$ & $0.004^{*}$ \\
\hline Physical science & $36(86.1)$ & $45(86.7)$ & 1.00 \\
\hline Mathematics & $36(91.7)$ & $45(95.6)$ & 0.65 \\
\hline \multicolumn{4}{|c|}{ NBT: average percentage obtained by students in the three NBT domains ( $t$-test) } \\
\hline \multirow[t]{2}{*}{ NBT domain } & $\begin{array}{l}\text { Group 1: students } \\
\text { highly successful in } \\
\text { physiology }(n=29)^{\dagger}\end{array}$ & $\begin{array}{l}\text { Group 2: students } \\
\text { who failed physiology } \\
(n=21)^{\dagger}\end{array}$ & \multirow[b]{2}{*}{$p$-value } \\
\hline & Average \% & Average \% & \\
\hline Academic literacy & 53.97 & 48.24 & 0.15 \\
\hline Quantitative literacy & 52.28 & 37.05 & $0.0006^{*}$ \\
\hline Mathematics & 47.35 & 43.05 & 0.22 \\
\hline \multicolumn{4}{|c|}{$\begin{array}{l}{ }^{*} p \leq 0.05 \text { statistically significant. } \\
\text { 'Students who wrote the NBT, where the results were available. }\end{array}$} \\
\hline
\end{tabular}

which includes physics. A surprising finding in our study was that there was no difference between the performances of the two groups for MA and physical science. Therefore, these subjects were found not to be good predictors of success. Similar observations with regard to MA have been made elsewhere in the world ${ }^{[9]}$ These findings are significant and somewhat ironic as, for many years (before 2008), our institution selected students solely on the basis of their performance in these two subjects, and they were not required to have life science (formerly biology) as a Matric subject.

\section{NBT results}

Even though our results and those of others suggest that MA was not a good predictor of success, it is interesting that when applying mathematical skills in problem-solving, as tested by the QL of the NBT, the successful group performed significantly better. This is supported by both the $t$-test (Table 1) and linear regression analysis. The latter showed that of AL, MA and QL, the last was the only statistically significant predictor of the final mark in physiology $(p=0.001)$.

This correlates with the pilot tests of the NBT Project in 2009, which indicated that only onequarter of all students tested were classified as 'proficient' in QL. ${ }^{[1]}$ The performance of the 
group that failed tended to be weaker for both $\mathrm{AL}$ and MA, but this is not supported by the statistical analysis. Our results therefore suggest that the NBT could have some value in predicting the success of candidates in their 2nd year of study.

\section{Conclusion}

The results suggest that a good performance in Matric English, the QL of the NBT, and excellent results in life science increase a student's chances of success in physiology in MB ChB II. This study will be repeated for the following two consecutive years to ensure reliability.

\section{Recommendations}

Institutions should investigate different parameters to be used in the selection process of medical students, of which the Matric performance in life science should be one of the factors. This preliminary study indicates the need to rethink the effectiveness of our selection criteria, redesign our selection process for $\mathrm{MB} \mathrm{ChB}$, and consider using the NBT. It will be desirable to seek to integrate the QL provision into the students' experience of the contexts studied in the physiology curriculum. Ideally, this could be done by ensuring that the lecturers in physiology are fully aware of the quantitative demands made by their curricula, the possible difficulties that students could experience, and knowing how to address these difficulties.

\section{References}

1. Mitchell KJ. Traditional predictors of performance in medical school. Acad Med 1990;65(3):149-158. 2. De Silva NR, Pathmeswaran A, de Silva N, et al. Admission to medical schools in Sri Lanka: Predictive validity of selection criteria. Ceylon Med J 2006;51(1):17-21.

3. Ramos SM, Croen L, Haddow S. Predictors of preclinical and clinical performance of minority medical students. J Natl Med Assoc 1986;78(7): 601-607.

4. Reede JY. Predictors of success in medicine. Clin Orthop Relat Res 1999;362:72-77.

5. Lehmann U, Andrews G, Sanders D. Change and Innovation at South African Medical Schools. Durban: Healt Systems Trust, 2000.

6. Frith V. Quantitative literacy interventions at University of Cape Town: Effects of separation from academic disciplines. Numeracy 2012;5(1):Article 3. [http://dx.doi.org/10.5038/1936-4660.5.1.3]

7. Foxcroft CD, Stumpf R. Matric: What is to be Done? CHET: Pretoria, 2005 .

8. Du Plessis L, Gerber D. Academic preparedness of students - an exploratory study. Journal for Transdisciplinary Research in Southern Africa 2012;8(1):81-94

9. Montague W, Odds FC. Academic selection criteria and subsequent performance. Med Educ 1990;24(2):151-157.

10. Jones RF, Thomae-Forgues M. Validity of the MCAT in predicting performance in the first two years of medical school. J Med Educ 1984:59(6):455-464.

11. Yeld, N. The National Benchmark Tests Project: Addressing student educational needs in the tertiary education system. In: Hofmeyer J, ed. Recession and Recovery. Cape Town: Institute for Justice and Reconciliation, 2009:76-83 